\title{
Rumen fluke (Calicophoron daubneyi) on Welsh farms: prevalence, risk factors and observations on co-infection with Fasciola hepatica
}

\author{
RHYS ALED JONES ${ }^{1}$, PETER M. BROPHY ${ }^{1}$, E. SIAN MITCHELL ${ }^{2}$ and \\ HEFIN WYN WILLIAMS ${ }^{1}$ \\ ${ }^{1}$ Institute of Biological, Environmental and Rural Sciences (IBERS), Aberystwyth University, Penglais, Abersystwyth, \\ Ceredigion, UK \\ ${ }^{2}$ Animal and Plant Health Agency (APHA), Carmarthen Veterinary Investigation Centre, Fob's Well Rd, Fohnstown, \\ Carmarthen SA31 3EZ, UK
}

(Received 10 Fune 2016; revised 2 September 2016; accepted 2 September 2016; first published online 1 November 2016)

\section{SUMMARY}

Reports of Calicophoron daubneyi infecting livestock in Europe have increased substantially over the past decade; however, there has not been an estimate of its farm level prevalence and associated risk factors in the UK. Here, the prevalence of C. daubneyi across 100 participating Welsh farms was recorded, with climate, environmental and management factors attained for each farm and used to create logistic regression models explaining its prevalence. Sixty-one per cent of farms studied were positive for $C$. daubneyi, with herd-level prevalence for cattle (59\%) significantly higher compared with flock-level prevalence for sheep $(42 \%, P=0.029)$. Co-infection between $C$. daubneyi and Fasciola hepatica was observed on $46 \%$ of farms; however, a significant negative correlation was recorded in the intensity of infection between each parasite within cattle herds ( $\mathrm{rho}=-0.358, P=0.007)$. Final models showed sunshine hours, herd size, treatment regularity against $F$. hepatica, the presence of streams and bog habitats, and Ollerenshaw index values as significant positive predictors for $C$. daubneyi $(P<0 \cdot 05)$. The results raise intriguing questions regarding $C$. daubneyi epidemiology, potential competition with $F$. hepatica and the role of climate change in $C$. daubneyi establishment and its future within the UK.

Key words: Calicophoron daubneyi, Fasciola hepatica, co-infection, cattle, sheep, logistic regression model, null modelling, UK.

\section{INTRODUCTION}

Rumen fluke (Paramphistomatidae spp.) are trematode parasites infecting ruminants worldwide. Traditionally rumen flukes were regarded as parasites mainly confined to tropical and sub-tropical areas. However, within European livestock, the presence in recent decades of high levels of rumen fluke, in particularly the species Calicophoron daub$n e y i$, is of potential concern. Calicophoron daubneyi was first recorded infecting cattle in Kenya in the 1950s (Dinnik, 1962), with confirmation of its occurrence in Europe from the 1970s (Sey, 1980) and the $\mathrm{UK}$ in 2012 (Gordon et al. 2012). In recent years, the UK has experienced an apparent sudden increase in the prevalence of rumen fluke, with the proportion of rumen fluke detected in ruminant submissions by passive veterinary surveillance increasing on average by $57 \%$ annually between 2010 and 2015 (VIDA, 2016a). High prevalence has been observed across Western Europe, with abattoir studies recording cattle prevalence levels of $29 \%$ in the UK (Sargison et al. 2016), 44.7\% in France

* Corresponding author: Institute of Biological, Environmental and Rural Sciences (IBERS), Aberystwyth University, Penglais, Abersystwyth, Ceredigion, UK. E-mail: hew05@aber.ac.uk
(Mage et al. 2002), $18 \cdot 8 \%$ in Spain (GonzalezWarleta et al. 2013), 28\% in Belgium (Malrait et al. 2015) and 52\% in Ireland (Toolan et al. 2015). Paramphistomosis (rumen fluke disease) has been reported in both cattle (Millar et al. 2012) and sheep (Mason et al. 2012) in the UK, however, UK passive veterinary surveillance has been detecting rumen fluke in larger proportions of cattle submissions compared with sheep submissions (VIDA, 2016a), while in Ireland prevalence levels have been shown to be lower in sheep compared with cattle (Toolan et al. 2015). In all cases of paramphistomosis, a heavy burden of juvenile fluke in the intestine has been attributed as the cause of the disease, with adult $C$. daubneyi believed to be well tolerated (Zintl et al. 2014). Nevertheless, adult C. daubneyi are known to induce inflammatory reactions in the rumen and reticulum (Fuertes et al. 2015), and in some instances may cause symptoms including bloat, loss of condition and the softening of feces in infected cattle (Alzieu and Dorchies, 2007). The potential threat of these symptoms to the UK livestock industry is heightened due to limited anthelmintic options for treatment, with oxyclozanide the only anthelmintic regarded as an effective paramphistomicide (Malrait et al. 2015). All published molecular level studies highlight 
C. daubneyi as the dominant and potentially the only Paramphistomatidae species present in UK livestock (Gordon et al. 2013; Huson et al. 2015), while earlier reports of Paramphistomum cervi in British livestock were only based on morphological identification (Pillers, 1922; Craig and Davies, 1937). Recent molecular analyses have also identified Paramphistomum leydeni infecting reindeer in south west England (VIDA, 2016b) and fallow deer in Ireland (O'Toole et al. 2014), leading to the possibility of alternative Paramphistomatidae spp. infecting UK livestock.

As with other trematode species, rumen fluke requires an intermediate snail host to complete its lifecycle, a process which sees the parasite exploit this host to develop and multiply rapidly. The prominent host of $C$. daubneyi is Galba truncatula (Dinnik, 1962; Degueurce et al. 1999; MartinezIbeas et al. 2013), a snail species, which thrives in the UKs consistently wet and mild climate. Galba truncatula is also the prominent intermediate host of the highly pathogenic liver fluke (Fasciola hepat$i c a$ ), a parasite which has been endemic in the UK for centuries (Dalton, 1998). As G. truncatula has recently been shown to host $C$. daubneyi in the UK (Jones et al. 2015), the potential epidemiological range of this parasite is also likely to be widespread.

Numerous predictive models of $F$. hepatica based on key climatic drivers for $G$. truncatula activity, including rainfall and temperature have been created over the past 60 years. The most prominent model, the Ollerenshaw index (Ollerenshaw and Rowlands, 1959), is widely used commercially as a regional fasciolosis risk guide for farmers (NADIS, 2016). In recent years, further climatic $F$. hepatica models have been created with the inclusion of either or both environmental factors (McCann et al. 2010) and farm management factors (Howell et al. 2015) in an attempt to predict fasciolosis occurrence at a finer scale. As well as increasing the accuracy of models, any farm management practices identified as risk factors for F. hepatica may inform veterinarians and farmers of best practices to negate fasciolosis risk. However, despite their similar reliance on $G$. truncatula, it remains to be resolved whether these models can accurately predict the occurrence of $C$. daubneyi due to differences in their epidemiology including, different egg hatching stimulus (Chryssafidis et al. 2015), timeframe of development within the snail (Dreyfuss, 2015), sensitivity to temperature at shedding (Abrous et al. 1999) and geotropism of cercariae (Dreyfuss et al. 2004). These epidemiological differences mean risk factors for $C$. daubneyi presence may vary significantly from $F$. hepatica, although risk factors for $G$. truncatula occurrence are likely to be confounding risk factors for both parasites. Calicophoron daubneyi models are currently scarce compared with models for $F$. hepatica. A Galician model identified decreasing rainfall and temperature, and increasing cattle density and slope as predictors of $C$. daubneyi prevalence in cattle (Gonzalez-Warleta et al. 2013), while an Italian Apennines model identified the presence of streams, springs or brooks, heathland and moorland as positive predictors of $C$. daubneyi (Cringoli et al. 2004). In these countries, the climate, environment and agricultural systems are very different to the $\mathrm{UK}$, and risk factors associated with $C$. daubneyi prevalence is therefore likely to vary within each country. There are also unanswered questions regarding the potential interaction between $C$. daubneyi and $F$. hepatica at intermediate host level in the UK (Jones et al. 2015), which could influence each parasite's distribution in the presence of the other. This consequence could be positive, due to a synergistic effect in infecting alternative snail species (Abrous et al. 1998), or negative, due to within-snail predation and competition for nutrients (Rondelaud et al. 2007).

In this case study, the prevalence of $C$. daubneyi on participating Welsh farms was recorded along with climatic, environmental and farm management factors for each farm. The aim was to create models explaining the presence of $C$. daubneyi on Welsh farms and to identify associated risk factors. Fasciola hepatica prevalence was also recorded with the aim of comparing the prevalence, infection intensity and risk factors of both parasites.

\section{MATERIALS AND METHODS}

\section{Questionnaire}

During 2015 farmers were invited to participate in the study through Young Farmers Clubs Wales, on social media and at various agricultural events. From September 2015 participants were instructed to fill an online questionnaire (Schmitz, 2015) containing 36 questions regarding the number and type of livestock on their farm, the presence of liver fluke and rumen fluke on their farm, their farms environmental features and management factors. Twenty-nine questions were closed, and seven were open ended. Open ended questions included months when cattle were housed, months of liver fluke and rumen fluke treatment, and which anthelmintics were used to treat against each parasite. In the case of anthelmintic use, answers given as the product brand name were transformed into the active drug class for that particular product. Participants were also asked to provide their full postal address and the postcode district location of each of their major holdings along with their proportional size. In total of 128 farmers completed the survey, all of which indicated their willingness to test their livestock for fluke. The project was approved by the Aberystwyth University Research Ethics Panel (project number 496). 


\section{Fecal sampling and testing}

A total of 128 packages containing gloves, $25 \mathrm{~mL}$ measuring apparatus, $50 \mathrm{~mL}$ tubes, question sheet and a prepaid return envelope were dispatched, and 100 were returned with appropriate samples between November 2015 and February 2016. Participants were instructed to collect $25 \mathrm{~mL}$ of feces from 20 individual cattle or sheep using a supplied measuring apparatus, before thoroughly mixing the samples and using the same apparatus to place $25 \mathrm{~mL}$ of feces in a supplied tube for posting to the laboratory. Farmers with both cattle and sheep were requested to repeat the process for both species and return separate $25 \mathrm{~mL}$ samples. The amount of feces requested for submission was selected to ensure return packages conformed to UN3373 biological sample postage regulations. Participants were also invited to submit details of sampled animals including, their age and most recent anthelmintic treatment against fluke species. Samples were stored at $4{ }^{\circ} \mathrm{C}$ and processed within $48 \mathrm{~h}$ of arrival at the laboratory. Fecal samples were tested for fluke infection using a sedimentation fecal egg count (FEC) technique. Approximately $20 \mathrm{~g}$ of feces were mixed thoroughly with water and washed through 300, 150 and $45 \mu \mathrm{m}$ mesh sieves. Materials including any fluke eggs collected on the $45 \mu \mathrm{m}$ sieves were washed into a $1 \mathrm{~L}$ measuring cylinders and allowed to sediment for $7 \mathrm{~min}$. The supernatant was removed via aspiration, with the process repeated 3-4 times until the sample was sufficiently clear. The samples were then stained with two drops of $1 \%$ methylene blue, placed in a $5 \mathrm{~cm}$ petri dish and viewed under a stereo microscope to count fluke eggs. Fluke eggs were differentiated via the golden and clear colour of $F$. hepatica and $C$. daubneyi eggs, respectively (Kajugu et al. 2015), before the numbers of eggs counted were divided with the weight of feces tested to calculate the eggs per gram (EPG) values.

\section{Identification of C. daubneyi in rumen fluke positive cases}

DNA from rumen fluke eggs that were isolated from feces via FEC were used to confirm the presence of $C$. daubneyi in each positive sample. Eggs and debris were resedimented until concentrated into a $0.5 \mathrm{~mL}$ centrifuge tube. If very low levels of eggs were observed during the FEC, the eggs were pipetted from the final FEC sedimentation to a $0 \cdot 5$ $\mathrm{mL}$ centrifuge tube. Four $0 \cdot 1-0.5 \mathrm{~mm}$ zirconia beads and $100 \mu \mathrm{L}$ of $5 \%$ Chelex $^{\circledR} 100$ (Bio-Rad, Hercules, USA) was added to the mixture and vortexed for $2 \mathrm{~min}$, prior to incubation firstly at $56^{\circ} \mathrm{C}$ for $60 \mathrm{~min}$, and secondly at $95^{\circ} \mathrm{C}$ for $10 \mathrm{~min}$. Samples were centrifuged at $15000 \mathrm{rpm}$ for $7 \mathrm{~min}$ with the supernatant diluted to the required concentration with nuclease free water (1/10 or $1 / 100)$. Each DNA extraction sample was subjected to an in-house polymerase chain reaction (PCR) protocol using C. daubneyi specific primers (F:5'-GTTTGTGTG GTTTGCCACGG-3'; R:5'-CTACCCCAAGCAG CCAC'TAC-3') that amplifies $169 \mathrm{bp}$ strands from the $C$. daubneyi cytochrome $c$ oxidase subunit 1 (cox1) gene (GenBank JQ815200). Primers were designed using Geneious software (Kearse et al. 2012) and were based on regions of the cox 1 gene unique to $C$. daubneyi in comparison with other Paramphistomatidae spp. and F. hepatica. Designed primer sequences were cross-referenced with NCBI sequences via primer-BLAST to ensure species specificity for its amplified sequences. For each sample, a $25 \mu \mathrm{L}$ master mix was created containing $12.5 \mu \mathrm{L}$ of MyTaq ${ }^{\mathrm{TM}}$ red mix (Bioline, London, UK), $50 \mu \mathrm{M}$ of primer, $1 \mu \mathrm{L}$ of the extracted DNA and nuclease free water. Each sample was subjected to PCR amplification consisting of an initial denaturation at $95^{\circ} \mathrm{C}$ for $2 \mathrm{~min}$ followed by 35 cycles consisting of stages of denaturation $\left(30 \mathrm{~s}\right.$ at $\left.95^{\circ} \mathrm{C}\right)$ annealing $(30 \mathrm{~s}$ at $65^{\circ} \mathrm{C}$ ) and extension $\left(30 \mathrm{~s}\right.$ at $\left.72^{\circ} \mathrm{C}\right)$, before a final $10 \mathrm{~min}$ extension phase at $72^{\circ} \mathrm{C}$. PCR products were visualized in $1 \%$ agarose gel stained with GelRed (Biotium, Hayward, USA) along with positive and negative controls, with $169 \mathrm{bp}$ band visualized in a well under UV light signifying a positive species identification for $C$. daubneyi. The presence or absence of other Paramphistomatidae spp. in sampled animals was not confirmed.

\section{Rumen fluke and liver fluke prevalence}

All statistical tests described in this section were performed in SPSS (v. 22). Prevalence data at farm, flock and herd level were attained by calculating the proportion of samples with EPG levels greater than zero at each respective level. To calculate the prevalence of $C$. daubneyi in participating farms from different regional areas, farms were categorized into six regions (north west, north east, Ceredigion, Montgomery, south west, south east) created using ordnance survey boundary line data (Ordnance Survey, 2016) in ArcMap (v 10.2.2). A chi-square test was performed to compare $C$. daubneyi prevalence levels on farms in western regions (north west, Ceredigion, south west) and eastern regions (north east, Montgomery, south east) of Wales. Differences in the prevalence of both $C$. daubneyi and $F$. hepatica between cattle herds and sheep flocks were analysed using a chi-square test. A Mann-Whitney U-test used to analyse differences in EPG levels of both parasites between cattle herds and sheep flocks for all cases where EPG levels were $>0$. As numerous farms in this study only had one livestock species present on their holding, the results of the two latter analyses could be skewed due to potential differences in the type 
of land seen on sheep only farms compared with cattle only farms. To combat this issue, parasite prevalence and intensity data from farms submitting samples for both livestock species were also analysed using paired difference tests (referred to as 'paired' samples hereafter). This allowed the prevalence and infection intensity of each parasite to be compared between cattle and sheep on each individual farm. This was analysed using a McNemar test (McNemar, 1947) for positive/negative cases, and a Wilcoxon ranked signed test for EPG values. The intensity of $F$. hepatica and $C$. daubneyi infections within herds, flocks and farms was also compared using spearman rank correlation (rho). Only herds and flocks, which were positive for either or both parasites were included in the analyses.

\section{Data sources}

Variables regarding farm structure, management and observed environmental features were extracted from questionnaire answers in Microsoft Excel. In instances where questions were directed at a specific species (cattle or sheep), answers were also adapted to be representative of farm level. For example, on farms where both cattle and sheep were present, the mean number of yearly $F$. hepatica treatments was calculated. Further variables were calculated using data from the questionnaire, including cattle grazing season length, grazing density (LSU/ha) and timing of $F$. hepatica treatment. Questionnaire postcode data were also used to georeference participating farms using ArcGIS (v 10.2.2). A full postcode for each farms address, or their largest holdings where applicable, was derived from the questionnaire and converted into geographical coordinates.

Observed climate data were sourced from the Met Office at $5 \mathrm{~km}^{2}$ resolution (Perry and Hollis, 2005). A detailed literature review was performed to identify potential climate factors on the C. daubneyi lifecycle, with each identified factor calculated from monthly observed data. For each variable, a value for the year 2015 and a value sourced from 2011 to 2015 (2012-2015 in the instance of sunshine hours due to changes in data format) were calculated. Climatic data were also used alongside extra-terrestrial radiation data (Duffie and Beckman, 2013) to calculate $5 \mathrm{~km}^{2}$ resolution Ollerenshaw index values (Mt) (Ollerenshaw and Rowlands, 1959) during the last 12 months and between 2011 and 2015.

Data regarding soil type, $\mathrm{pH}$ and moisture levels at $1 \mathrm{~km}^{2}$ resolution were sourced from the Centre for Ecology and Hydrology (CEH) (Henrys et al. 2012; Henrys et al. 2014), and soil mineral levels were sourced from the British geological survey (BGS) (Rawlins et al. 2012). A literature review of minerals shown to either have been included in predictive models for $F$. hepatica or known to have an effect on Lymnaeidae snail biology determined the choice of soil minerals to analyse. ArcMap (v 10.2.2) was used to extract all climate and environmental data using the raster to point function.

\section{Statistical analysis of C. daubneyi and F. hepatica presence}

Presence data for $C$. daubneyi and $F$. hepatica along with the data sourced above was statistically analysed with the aim of creating models to explain the presence and absence of the parasites on the study farms, cattle herds and sheep flocks.

Univariate analysis. Variables regarded as being potential predictor values for $C$. daubneyi and $F$. hepatica were selected for inclusion as potential model variables via univariate analysis. Univariate analysis was performed using the Pearson chisquare test for binary variables and the MannWhitney U-test for numerical variables in SPSS (v 22.0). For each test, a significance value of $P<$ $0 \cdot 10$ was required for each variable to be selected for the next stage of analysis.

Logistic regression. Binary logistic regression was performed on the data from the univariate analysis to create candidate models explaining the presence or absence of $C$. daubneyi. Farms with $C$. daubneyi EPG values $>0$ for either or both cattle and sheep samples were considered as $C$. daubneyi positive, while farms with $C$. daubneyi EPG of 0 from all samples were considered negative. Forward Wald and backward Wald logistic regression with a probability for stepwise of $P<0.05$ for entry and $P>$ $0 \cdot 10$ for removal was performed in SPSS (v.22) to create candidate models. Odds ratios and their respective $95 \%$ confidence intervals were calculated to quantify the strength of each variable's association with $C$. daubneyi prevalence within each model. However, when prevalence is above $10 \%$, odds ratios can overestimate risk (Zhang and $\mathrm{Yu}, 1998$ ) and thus any interpretation of odds ratios in these instances must be made cautiously. This process was repeated to create cattle herd $(n=76)$ and sheep flock $(n=90) C$. daubneyi models. The above process was also repeated to create a farm level $F$. hepatica model. However, as 14 farms had recently treated all sampled animals with flukicide prior to submission of their FEC samples, only 86 farms were used to create this model.

Multi-model selection and fitting. Each candidate model was tested for goodness of fit via the Hosmer-Lemeshow test with non-significant chisquare statistic values $(P>0.05)$ indicating a model with goodness of fit. The small sample corrected Akaike information criterion (AICc) (Burnham and 
Table 1. Descriptive statistics regarding the number of participating farms, herds and flocks and their mean size

\begin{tabular}{lccc}
\hline \hline & $n$ farms & Mean size/animal $n$ & Range \\
\hline Farm size & & & \\
$\quad$ Farm area (ha) & 100 & 138 & $3-480$ \\
Farm enterprises & & & $60-550$ \\
$\quad$ Dairy herds (adult cattle) & 8 & 36 & $5-150$ \\
Suckler cow herds (adult cattle) & 70 & 68 & $5-1100$ \\
Heifer/steers herds ( $>12$ months of age) & 85 & 595 & $50-4000$ \\
Sheep flocks (adult sheep) &
\end{tabular}

Anderson, 2002) was calculated with the SAM (v4.0) (Rangel et al. 2010) software for candidate models identified by stepwise model building. The model with the lowest AICc values were considered the models with the most empirical support (Burnham and Anderson, 2002) and chosen for further predictive testing.

Model predictive testing. Interpreting the predictive performance of logistic regression models through metrics such as the area under the curve (AUC) is an important part of their evaluation (Fielding and Bell, 1997), but one fraught with dangers such as the inflation of metrics by spatial patterns in the data leading to inflated Type I errors (Lobo et al. 2008). Consequently, the AUC values of the chosen models were compared against appropriate null models using the method proposed by Beale et al. (2008) and adapted by Williams et al. (2015). For each selected model, 99 null models were created and these null models retained the spatial patterns in the observed distribution of $C$. daubney $i$ on farms. In each instance, models were randomly split 1000 times into training and testing points at a ratio of 60:40, respectively. The median AUC of each test model across 1000 splits were then calculated. The chosen models were adjudged to have identified a prediction greater than expected by chance if their median AUC were higher than the median AUC values of 95 of accompanying null models. See Williams et al. (2015) for full details of the methodology used.

\section{RESULTS}

\section{Descriptive statistics}

One hundred farms submitted samples for testing the presence or absence of $C$. daubneyi. Details on the number of herd types and flocks along with the average size of each can be seen in Table 1 .

Forty-nine per cent of participants were aware of rumen fluke prior to this study, with $10 \%$ indicating rumen fluke was or had been present on their farms. There was no significant relationship between a participants prior knowledge of rumen fluke and its presence on their farm $\left(\chi^{2}=0 \cdot 749, P=0 \cdot 387\right)$. Six per cent of participating farmers had recently treated directly against rumen fluke with an oxyclozanide product, with $5 \%$ using the anthelmintic to treat against $F$. hepatica over the past 12 months.

\section{Rumen fluke species ID}

DNA from 81 rumen fluke egg samples (44 cattle; 37 sheep) were extracted and screened for $C$. daubneyi DNA. All 81 samples $(100 \%)$ were positive for $C$. daubneyi.

\section{Prevalence}

Sixty-one per cent of farms were positive for $C$. daubneyi, while $68 \%$ were positive for $F$. hepatica, with only $17 \%$ of farms negative for both. Co-infection of both $C$. daubneyi and $F$. hepatica was seen on $46 \%$ of farms. The prevalence of $C$. daubneyi across six regional areas of Wales can be seen in Fig. 1. Calicophoron daubneyi prevalence was significantly higher in western regions (NW, C, SW) of Wales compared with eastern regions $(\mathrm{NE}, \mathrm{M}, \mathrm{SE})\left(\chi^{2}=\right.$ 7·507. $P=0 \cdot 006)$.

The prevalence of $C$. daubneyi and F. hepatica in herds and flocks are presented in Table 2. Fiftynine per cent of cattle herds sampled in this study were positive for $C$. daubneyi, compared with a significantly lower prevalence level of $42 \%$ in sampled sheep flocks $(P=0.029)$. The prevalence levels of $C$. daubneyi in paired cattle herds (59\%) was significantly higher compared with their sheep flock counterparts $(42 \%)$ when using a paired difference test $(P=0.035)$ on individual farms, which had submitted both cattle and sheep samples. There was no significant difference between the EPG levels of $C$. daubneyi within positive sheep flocks and cattle herds in either normal $(P=0.596)$ or paired $(P=$ $0 \cdot 131$ ) analysis (Table 3 ).

There was no significant difference between prevalence levels of $F$. hepatica in cattle herds and sheep flocks in the total submitted samples $(P=$ $0.916)$ and paired $(P=0.851)$ samples (Table 2). Fasciola hepatica EPG level were however, significantly higher in positive sheep flocks compared 


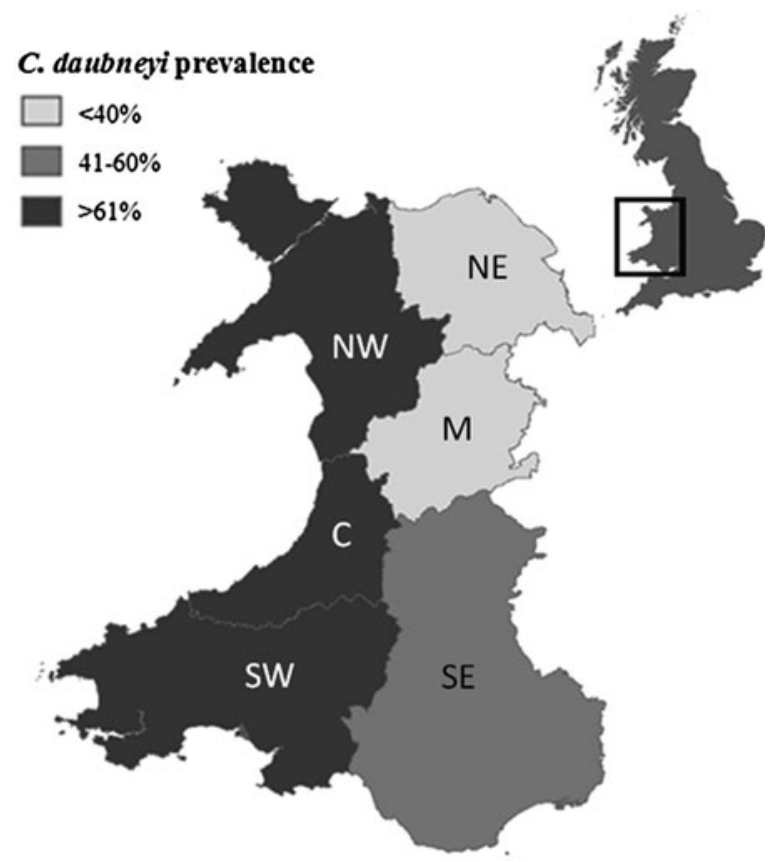

Fig. 1. Prevalence of $C$. daubneyi in regional areas of Wales: NW - north west $(n=19) \mathrm{NE}-$ north east $(n=14)$, C - Ceredigion $(n=19), \mathrm{M}-$ Montgomery $(n=13)$, SW south west $(n=15), \mathrm{SE}-$ south east $(n=20)$. Prevalence of C. daubneyi was significantly higher $\left(\chi^{2}=7 \cdot 507, P=0.006\right)$ in western regions $(\mathrm{NW}, \mathrm{C}, \mathrm{SW})(73 \cdot 6 \%)$ compared with eastern regions (NE, M, SE) $(46 \cdot 8 \%)$. Contains OS data ${ }^{\odot}$ Crown copyright and database right (2016).

with positive cattle herds for total samples $(P<$ $0 \cdot 001)$ and paired samples $(P=0 \cdot 004)$ (Table 3$)$.

\section{Fluke species correlation}

A significant negative correlation between EPG levels of $C$. daubneyi and $F$. hepatica was recorded for herds (rho $=-0 \cdot 358, P=0 \cdot 007)$, with a non-significant (rho $=-0 \cdot 199, P=0 \cdot 11$ ) negative correlation recorded for flocks.

\section{Logistic regression models of $\mathrm{C}$. daubneyi and} $\mathrm{F}$. hepatica presence or absence

Univariate analysis selected 20, 24 and 14 variables as potential predictors of $C$. daubneyi at farm, herd and flock level, respectively, for input into logistic regression analysis (Supplementary Table 1). The final models explaining the prevalence of $C$. daubney $i$ on Welsh farms, in cattle herds and sheep flocks are seen in Table 4. The farm model identified four positive predictors for C. daubneyi on Welsh farms; the cattle model identified five positive predictors for $C$. daubneyi in cattle herds, while the sheep model identified two positive predictors for C.daubney $i$ in sheep flocks. Univariate analysis selected 17 variables as potential predictors of $F$. hepatica at farm level, and four significant predictors were selected in the final model (Table 4). All final models AICc values were at least two points lower than the AICc values of other candidate models, including models created using only climate variables.

\section{DISCUSSION}

This study is the first to record the on-farm prevalence of $C$. daubneyi in any area within the UK. This initial estimate of $C$. daubneyi prevalence $(61 \%)$ indicates that it is established in Wales, a finding which is supported by the increasing prevalence of rumen fluke observed by passive veterinary surveillance across the UK since 2010 (VIDA, 2016a). The logistic regression models created are also the first models explaining the prevalence of C. daubneyi in an area of the UK. Each final model created included both climate and environmental/ management factors, and were superior to climate only models at the model selection stage. This indicates the importance of using environmental and management factors alongside climate variables when modelling $C$. daubneyi prevalence at farm level, as is the case with $F$. hepatica (Bennema et al. 2011).

Despite our finding that $C$. daubneyi may be very common in Wales; it is not universally known within the Welsh agricultural community. Calicophoron daubneyi prevalence was shown to be lower than $F$. hepatica despite the fact that most farms in the study treated against $F$. hepatica and not $C$. daubneyi. Calicophoron daubneyi may therefore be in the process of spreading and colonizing farms and regions in Wales. The high proportion of farms harbouring co-infection of $C$. daubneyi and F. hepatica within their livestock (46\%) suggests the parasites share a similar geographic range in Wales. Similarities were also observed between $C$. daubneyi and $F$. hepatica risk factors, with environmental features linked to G. truncatula presence such as presence/density of boggy habitats, soil factors and water sources important variables in models for both parasites. In contrast to the $C$.daubneyi models, climate variables were absent from the $F$. hepatica model, which may be explained by the importance of environmental factors in previous F. hepatica predictive models (McCann et al. 2010; Bennema et al. 2011).

A negative correlation was recorded between the intensity of infection of each parasite in both cattle herds and sheep flocks. The high levels of $C$. daubneyi and low levels of $F$. hepatica seen in numerous cases could be explained by Welsh farmers treating against $F$. hepatica with anthelmintics not active against $C$. daubneyi. Yet treatment regimen alone does not explain the decreasing EPG levels of $C$. daubneyi seen in the presence of increasing F. hepatica as none of the small proportion of participating farms in this study that had recently used oxyclozanide in their livestock had higher EPG levels of 
Table 2. Prevalence of $C$. daubneyi and F. hepatica within cattle herds and sheep flocks in both the total submitted samples and paired samples

\begin{tabular}{|c|c|c|c|c|c|c|}
\hline & \multicolumn{3}{|l|}{ Total samples } & \multicolumn{3}{|l|}{ Paired samples } \\
\hline & Prevalence $(n)$ & $\chi^{2}$ & Sig. & Prevalence $(n)$ & $\chi^{2}$ & Sig. \\
\hline Fasciola hepatica cattle & $55 \%(76)$ & $0 \cdot 11$ & $0 \cdot 916$ & $58 \%(66)$ & $0 \cdot 36$ & $0 \cdot 851$ \\
\hline Fasciola hepatica sheep & $54 \%(90)$ & & & $55 \%(66)$ & & \\
\hline Calicophoron daubneyi cattle & $59 \%(76)$ & $4 \cdot 76$ & $0 \cdot 029$ & $59 \%(66)$ & $7 \cdot 63$ & $0 \cdot 035$ \\
\hline Calicophoron daubneyi sheep & $42 \%(90)$ & & & $42 \%(66)$ & & \\
\hline
\end{tabular}

Table 3. Mean EPG levels for C. daubneyi and F. hepatica in positive cattle herds and sheep flocks in both the total submitted samples and paired samples

\begin{tabular}{|c|c|c|c|c|c|c|c|c|c|}
\hline & \multirow[b]{2}{*}{$\begin{array}{l}\text { Max } \\
\text { EPG }\end{array}$} & \multicolumn{4}{|c|}{ Total samples } & \multicolumn{4}{|c|}{ Paired samples } \\
\hline & & $\begin{array}{l}\text { Mean } \\
\text { EPG }(n)\end{array}$ & S.D. & $\mathrm{U}$ & Sig. & $\begin{array}{l}\text { Mean } \\
\text { EPG }(n)\end{array}$ & S.D. & $Z$ & Sig. \\
\hline Fasciola hepatica EPG cattle & 5 & $0 \cdot 96(42)$ & $1 \cdot 1$ & 399 & $0 \cdot 000$ & $1 \cdot 02(23)$ & $1 \cdot 19$ & $-2 \cdot 92$ & $0 \cdot 004$ \\
\hline Fasciola hepatica EPG sheep & 300 & $19 \cdot 76(49)$ & $49 \cdot 32$ & & & $22 \cdot 89(23)$ & $32 \cdot 49$ & & \\
\hline Calicophoron daubneyi $\mathrm{EPG}$ cattle & 70 & $9 \cdot 94(45)$ & $14 \cdot 39$ & -530 & $0 \cdot 596$ & $11 \cdot 37(22)$ & $12 \cdot 93$ & $-1 \cdot 51$ & $0 \cdot 131$ \\
\hline Calicophoron daubneyi EPG sheep & 113 & $9.93(38)$ & $20 \cdot 44$ & & & $8.99(22)$ & $12 \cdot 62$ & & \\
\hline
\end{tabular}

EPG, eggs per gram.

$F$. hepatica. This raises potential intriguing questions regarding the epidemiology of each parasite. Despite their apparent preference for the same intermediate snail host, it is unclear whether each parasite's different epidemiology leads to farms being more suited to one fluke species than the other, or whether potential competition between each parasite at the intermediate snail stage occurs. C. daubneyi and $F$. hepatica are known to eliminate each other when dually infecting $G$. truncatula (Rondelaud et al. 2007) while the presence of other trematode have been shown to suppress $F$. hepatica levels within snail populations (Gordon and Boray, 1970; Whitelaw and Fawcett, 1982; Goumghar et al. 2000). If competition does occur, it could explain the reason for variables regarding treatment against $F$. hepatica being a positive predictor for $C$. daubney $i$ in final models. By treating against $F$. hepatica regularly, especially during spring (a positive predictor for $C$. daubneyi presence in the cattle model), the number of $F$. hepatica eggs shed onto pasture may be reduced, potentially freeing $G$. truncatula snails to be infected with $C$. daubneyi. However, caution must be maintained when interpreting these results, as treatment regularity may be partly determined by historic $F$. hepatica issues, which in turn may be partly determined by the density of G. truncatula habitats. Despite this, an increasing efficacy of treatment for $F$. hepatica in France has been suggested as a reason for their recorded increase in paramphistomosis over the past 25 years (Mage et al. 2002; Rieu et al. 2007). In the UK, the growing threat of triclabendazole resistance (Gordon et al. 2012) is causing major issues with $F$. hepatica treatment efficacy (Sargison et al. 2016). Thus, it is hypothesized that the varying efficacy of a farm's treatment regimen against $F$. hepatica could determine, which parasite prevails in a competition to dominate a farm's endogenous $G$. truncatula populations and therefore be capable of infecting livestock at high intensities. Furthermore, in an instance where $C$. daubneyi could suppress $F$. hepatica through competition, farms could in theory benefit from the presence of $C$. daubneyi. For example, it is currently believed that a heavy burden of juvenile C. daubneyi is required to cause clinical disease in livestock (Mason et al. 2012; Millar et al. 2012), with adult paramphistomes well tolerated (Zintl et al. 2014). In comparison, heavy infections of both juvenile and adult $F$. hepatica are known to cause severe losses in livestock (Dargie, 1987), with production losses also associated with lighter burdens (Schweizer et al. 2005). However, further research would be required on both the dynamics of this potential competition, as well as the pathogenicity of both juvenile and adult $C$. daubneyi prior to any implementation of strategies to take advantage of this potential phenomenon.

Differences in the prevalence of $C$. daubneyi between cattle herds and sheep flocks were also observed, with prevalence higher in cattle compared with sheep. This coincides with UK passive veterinary surveillance data (VIDA, 2016a) and data from Irish abattoirs and veterinary surveillance (Toolan 
Table 4. Logistic regression models explaining the prevalence of $C$. daubneyi on Welsh farms, and in cattle herds, and sheep flocks

\begin{tabular}{|c|c|c|c|c|c|c|c|c|c|c|c|c|}
\hline Model & Variable & HL & AUC & $\mathrm{AICc}$ & NMR & $\mathrm{B}$ & S.E. & Wald & Sig. & Odds Ratio & Lower 95\% CI & Upper $95 \% \mathrm{CI}$ \\
\hline \multirow[t]{7}{*}{ Farm C. daubneyi } & & $0 \cdot 78$ & $0 \cdot 85$ & $103 \cdot 2$ & $1 \mathrm{st}$ & & & & & & & \\
\hline & Constant & & & & & $-15 \cdot 022$ & $3 \cdot 663$ & $16 \cdot 87$ & 0 & 0 & - & - \\
\hline & \multicolumn{5}{|c|}{ Number of heifers/steers (Over 12 months) } & 0.03 & 0.009 & $10 \cdot 66$ & $0 \cdot 001$ & $1 \cdot 03$ & $1 \cdot 012$ & $1 \cdot 049$ \\
\hline & \multicolumn{5}{|c|}{$\begin{array}{l}\text { Mean annual treatment of livestock against } \\
F . \text { hepatica }\end{array}$} & $1 \cdot 359$ & $0 \cdot 479$ & $8 \cdot 06$ & $0 \cdot 005$ & $3 \cdot 89$ & $1 \cdot 523$ & $9 \cdot 941$ \\
\hline & \multicolumn{5}{|c|}{ Presence of streams or drainage ditches } & $3 \cdot 997$ & $1 \cdot 453$ & $7 \cdot 57$ & $0 \cdot 006$ & $54 \cdot 46$ & $3 \cdot 154$ & $940 \cdot 12$ \\
\hline & \multicolumn{5}{|c|}{ Presence of bog habitats } & $1 \cdot 342$ & $0 \cdot 735$ & $3 \cdot 34$ & $0 \cdot 068$ & $3 \cdot 83$ & $0 \cdot 906$ & $16 \cdot 169$ \\
\hline & \multicolumn{5}{|c|}{ Mean daily sunshine hours: MJJ (2015) } & $1 \cdot 308$ & $0 \cdot 479$ & $8 \cdot 08$ & $0 \cdot 004$ & $3 \cdot 7$ & $1 \cdot 501$ & $9 \cdot 12$ \\
\hline \multirow[t]{8}{*}{ Cattle $C$. daubneyi } & & $0 \cdot 74$ & $0 \cdot 86$ & $86 \cdot 2$ & $1 \mathrm{st}$ & & & & & & & \\
\hline & Constant & & & & & $-17 \cdot 867$ & $4 \cdot 922$ & $13 \cdot 18$ & 0 & 0 & - & - \\
\hline & \multicolumn{5}{|c|}{ Number of cattle over 12 months } & $0 \cdot 009$ & $0 \cdot 004$ & $3 \cdot 67$ & $0 \cdot 055$ & $1 \cdot 009$ & 1 & $1 \cdot 017$ \\
\hline & \multicolumn{5}{|c|}{ Treatment of cattle against $F$. hepatica in spring } & $2 \cdot 808$ & $1 \cdot 19$ & $5 \cdot 56$ & $0 \cdot 018$ & $16 \cdot 57$ & $1 \cdot 607$ & $170 \cdot 85$ \\
\hline & \multicolumn{5}{|c|}{ Presence of bog habitats } & $1 \cdot 714$ & $0 \cdot 77$ & $4 \cdot 96$ & 0.026 & $5 \cdot 55$ & $1 \cdot 228$ & $25 \cdot 108$ \\
\hline & \multicolumn{5}{|c|}{ Water flowing from other farm } & $2 \cdot 019$ & 0.986 & $4 \cdot 19$ & $0 \cdot 041$ & $7 \cdot 53$ & $1 \cdot 091$ & $51 \cdot 99$ \\
\hline & \multirow{2}{*}{\multicolumn{5}{|c|}{$\begin{array}{l}\text { Mt Summer } 2015 \\
\text { Sunshine hours: MJJ (2012-2015) }\end{array}$}} & $0 \cdot 013$ & $0 \cdot 005$ & $6 \cdot 52$ & $0 \cdot 011$ & $1 \cdot 013$ & $1 \cdot 003$ & $1 \cdot 024$ \\
\hline & & & & & & $1 \cdot 565$ & $0 \cdot 654$ & $5 \cdot 73$ & $0 \cdot 017$ & $4 \cdot 79$ & $1 \cdot 328$ & $17 \cdot 226$ \\
\hline \multirow[t]{4}{*}{ Sheep C. daubneyi } & & $0 \cdot 52$ & $0 \cdot 80$ & $99 \cdot 3$ & $1 \mathrm{st}$ & & & & & & & \\
\hline & \multirow{3}{*}{\multicolumn{5}{|c|}{$\begin{array}{l}\text { Constant } \\
\text { Number of heifers/steers (over } 12 \text { months) } \\
\text { Sunshine hours: MJJ (2012-2015) }\end{array}$}} & $-14 \cdot 279$ & $3 \cdot 977$ & $12 \cdot 89$ & 0 & 0 & - & - \\
\hline & & & & & & $0 \cdot 023$ & $0 \cdot 008$ & $8 \cdot 06$ & $0 \cdot 005$ & $1 \cdot 024$ & $1 \cdot 007$ & $1 \cdot 04$ \\
\hline & & & & & & $2 \cdot 189$ & $0 \cdot 643$ & $11 \cdot 59$ & $0 \cdot 001$ & 8.92 & $2 \cdot 531$ & $31 \cdot 45$ \\
\hline \multirow[t]{6}{*}{ Farm F. hepatica } & & $0 \cdot 57$ & $0 \cdot 87$ & $66 \cdot 8$ & $1 \mathrm{st}$ & & & & & & & \\
\hline & \multirow{2}{*}{\multicolumn{5}{|c|}{ Constant }} & $-6 \cdot 638$ & $2 \cdot 329$ & $8 \cdot 13$ & 0 & 0 & - & - \\
\hline & & & & & & $-1 \cdot 672$ & 0.779 & $4 \cdot 61$ & 0.032 & $0 \cdot 188$ & $0 \cdot 041$ & $0 \cdot 865$ \\
\hline & \multicolumn{5}{|c|}{ Soil CU } & $0 \cdot 286$ & 0.099 & $8 \cdot 43$ & 0.004 & $1 \cdot 331$ & $1 \cdot 097$ & $1 \cdot 615$ \\
\hline & \multirow{2}{*}{\multicolumn{5}{|c|}{ Access to natural water }} & $2 \cdot 005$ & 0.884 & $5 \cdot 15$ & $0 \cdot 023$ & $7 \cdot 426$ & $1 \cdot 313$ & 41.987 \\
\hline & & \multicolumn{3}{|c|}{ Percentage of fields with bog habitats } & & $1 \cdot 509$ & $0 \cdot 548$ & $7 \cdot 60$ & $0 \cdot 006$ & $4 \cdot 524$ & $1 \cdot 547$ & $13 \cdot 233$ \\
\hline
\end{tabular}

AIC, Akaike information criterion; AUC, area under the curve; CI, confidence interval; HL, Hosmer-Lemeshow; NMR, Null Model Rank; s.E., standard error; MJJ; May -July. 
et al. 2015). One suggested reason for the latter finding in Ireland was that sheep graze rougher pasture compared with cattle; however, this seems to be an unlikely factor in our results as there was no significant difference between $F$. hepatica prevalence in cattle and sheep, which indicates a similar exposure to $G$. truncatula habitats for each ruminant species. It has been shown that another Paramphistomum species, C. microbothrium, is better suited to infecting cattle compared with sheep, with the parasite having an increased lifespan, and is known to migrate quicker and exhibit increased growth and egg laying ability when infecting cattle (Horak, 1967). Calicophoron daubneyi may similarly be better suited to infecting cattle compared with sheep, however, there was no significant difference in the EPG levels seen in positive herds and flocks, in fact the highest EPG levels for $C$. daubneyi in this study was seen in a sheep flock. Ovine paramphistomosis has also been reported in the UK (Mason et al. 2012), which indicates that C. daubneyi should not be disregarded as a pathogenic parasite of sheep. The importance of cattle in the epidemiology of $C$. daubney $i$ was further emphasised in each model, where either the total number of cattle or number of heifers or steers present on a farm were selected as positive predictors for C. daubneyi. An increasing herd size may increase the sources of $C$. daubneyi eggs shedding onto pasture and thus parasite spread within a farm, but may also lead to an increased risk of buying in the parasite with increasing herd size a potential proxy for herd turnover rate (Reilly and Courtenay, 2007). This was highlighted in the questionnaire data where farms buying in cattle had significantly larger herd sizes. This also highlights the role of biosecurity in disease prevention; with $C$. daubneyi seemingly well-established less than a decade since significant reports of its occurrence in the UK began.

Other variables which could have biosecurity implications that were included as positive predictors in the best performing models were the 'presence of livestock accessible streams or drainage ditches' and 'water flowing from other farms'. The inclusion of these variables may be a measure of the presence of intermediate host snail habitats, with muddy areas surrounding streams and ditches a common habitat for G. truncatula similarly to boggy pastures, which was also a positive predictor for $C$. daubneyi in two of the final models. However, streams are also potential movement corridors for $G$. truncatula snails, with data from France suggesting $G$. truncatula snails can travel upstream and contaminate pasture free from livestock with $F$. hepatica metacercariae (Rondelaud et al. 2005). The role of streams in the spread of $C$. daubneyi and potentially TCBZ resistant strains of $F$. hepatica in the UK is therefore worthy of further investigation.

The only direct climate variable to be included in all of the final $C$. daubneyi models was sunshine hours. The exact reason for this inclusion is unclear; however, $C$. daubneyi eggs are known to be more dependent on light as a hatching stimulus compared with $F$. hepatica eggs (Chryssafidis et al. 2015). If this is the reason for sunshine's inclusion in each model it may suggest that eggs in areas receiving longer levels of sunshine may have higher hatching success rates, leading to increasing lifecycle opportunities. A calculated Ollerenshaw index value for the summer of 2015 was also a positive predictor of $C$. daubney $i$ in the cattle model. Although its effect on the model was small, potentially due to the limited impact of between-year weather variation on between-farm fluke prevalence (McCann et al. 2010), its inclusion may unsurprisingly suggests that climate predictors of fasciolosis may also have predictive power regarding $C$. daubneyi. This may partly explain the higher prevalence of $C$. daubneyi seen in participating farms from western regions of Wales, with western Wales shown to be one area of the $\mathrm{UK}$ at most risk of fasciolosis both historically and in future forecasts when using the Ollerenshaw model (Fox et al. 2011). A westerly trend of increased rumen fluke detection in passive veterinary surveillance has similarly been observed in Wales and throughout the UK (VIDA, 2016a), which would also suggest that the traditional climate drivers of $F$. hepatica prevalence are also important factors for C. daubneyi. To enhance our understanding of the relationship between climatic variables and $C$. daubneyi prevalence, it would be necessary to analyse a dataset on a wider scale.

It remains unclear how and why $C$. daubneyi has apparently become so prevalent in the UK in recent years, and questions remain regarding its origins. It is possible that low levels of $C$. daubneyi in the UK may have been overlooked previously due to the perceived presence of $P$. cervi as the dominant Paramphistomatidae sp. in UK livestock (Gordon et al. 2013), and its non-pathogenicity at low levels (Zintl et al. 2014). In this instance, it could be suggested that a decrease in the popularity of 'old' anthelmintic products, including oxyclozanide, following the licencing of TCBZ in the mid 80 s would have allowed $C$. daubney $i$ to ultimately increase its prevalence in UK livestock. There is also a possibility that $C$. daubneyi parasites may have recently been imported into the UK in infected animals, with cattle imports to the UK increasing substantially in the aftermath of the 2001 foot and mouth disease outbreak (Mitchell et al. 2005), which coincides with a period where $C$. daubneyi levels in France had just increased significantly (Mage et al. 2002). In either or both instances, it is likely that climate change will have played a role in the recent establishment of $C$. daubneyi in the UK. Since 1970, increasing rainfall and temperatures have seen the UK climate become more suitable for G. truncatula populations (Fox et al. 2011), a 
factor which has seen increasing reports of fasciolosis (Pritchard et al. 2005) and may have had a similar positive effect on $C$. daubneyi. Increasing annual hours of sunshine have also been observed in the UK over the past 50 years (Met-Office, 2016), which may have also contributed to $C$. daubneyi establishment if indeed sunshine duration is a driver for its prevalence. Climate change could also lead to future increases in $C$. daubneyi prevalence due to further climate change forecast of increases in climate suitability for G. truncatula (Fox et al.2011).

\section{Concluding remarks}

This study was the first farm level survey for $C$. daubneyi in any area of the UK, with the results indicating $C$. daubneyi is endemic in Wales. The study has also raised important questions regarding differing prevalence levels between ruminant species, and potential competition between $C$. daubneyi and $F$. hepatica. To answer these questions further research on the epidemiology of $C$. daubneyi at a finer and broader scale will be required. Finally, this study produced the first model for $C$. daubneyi in an area of the UK. The predictors identified may be used in future as a basis to further study $C$. daubneyi epidemiology and to develop models of further value to farmers and veterinarians in predicting and combating $C$. daubneyi occurrence and paramphistomosis risk.

\section{SUPPLEMENTARY MATERIAL}

The supplementary material for this article can be found at https://doi.org/10.1017/S0031182016001797

\section{ACKNOWLEDGEMENTS}

The authors would like to thank all farmers participating in this project; the staff at YFC Wales; Dr Martin Vickers for assistance in creating project website; Dan Hollis of the UK Met Office for assistance in providing observed climate data; farmers and veterinarians who have contributed to the VIDA dataset; and two anonymous reviewers for their constructive comments, which greatly improved the manuscript.

\section{FINANCIAL SUPPORT}

Rhys Aled Jones gratefully acknowledges the Dr Owen Price scholarship for funding his Ph.D. The project was funded by the Coleg Cymraeg Cenedlaethol (to H. W. W.).

\section{REFERENCES}

Abrous, M., Rondelaud, D., Dreyfuss, G. and Cabaret, J. (1998). Unusual transmission of the liver fluke, Fasciola hepatica, by Lymnaea glabra or Planorbis leucostoma in France. Fournal of Parasitology 84, 1257-1259.

Abrous, M., Rondelaud, D. and Dreyfuss, G. (1999). Paramphistomum daubneyi and Fasciola hepatica: influence of temperature changes on the shedding of cercariae from dually infected Lymnaea truncatula. Parasitology Research 85, 765-769.

Alzieu, P. J. and Dorchies, P. (2007). Reemergence of cattle paramphistomiasis in France: current review of epidemiology, pathophysiology and diagnosis. Bulletin de l'Académie Vétérinaire de France 160, 93-99.

Beale, C. M., Lennon, J. J. and Gimona, A. (2008). Opening the climate envelope reveals no macroscale associations with climate in European birds. Proceedings of the National Academy of Sciences of the United States of America, 105, 14908-14912. http://dx.doi.org/10.1073/pnas.0803506105 Bennema, S. C., Ducheyne, E., Vercruysse, J., Claerebout, E., Hendrickx, G. and Charlier, J. (2011). Relative importance of management, meteorological and environmental factors in the spatial distribution of Fasciola hepatica in dairy cattle in a temperate climate zone. International Fournal for Parasitology 41, 225-233. http://dx.doi.org/10.1016/j.ijpara. 2010.09.003

Burnham, K.P. and Anderson, D. R. (2002). Model Selection and Multimodel Inference a Practical Information-Theoretic Approach. Springer, New York, NY, USA.

Chryssafidis, A. L., Fu, Y., De Waal, T. and Mulcahy, G. (2015). Standardisation of egg-viability assays for Fasciola hepatica and Calicophoron daubneyi: a tool for evaluating new technologies of parasite control. Veterinary Parasitology 210, 25-31. http://dx.doi.org/10.1016/j. vetpar.2015.03.005

Craig, J. F. and Davies, G. O. (1937). Paramphistomum cervi in Sheep. Veterinary Record 49, 1116-1117.

Cringoli, G., Taddei, R., Rinaldi, L., Veneziano, V., Musella, V., Cascone, C., Sibilio, G. and Malone, J.B. (2004). Use of remote sensing and geographical information systems to identify environmental features that influence the distribution of paramphistomosis in sheep from the southern Italian Apennines. Veterinary Parasitology 122, 15-26. Dalton, J. P. (1998). Fasciolosis. CABI Pub., Wallingford, UK, New York, NY, USA.

Dargie, J. D. (1987). The impact on production and mechanisms of pathogenesis of trematode infections in cattle and sheep. International fournal for Parasitology 17, 453-463. http://dx.doi.org/10.1016/0020-7519(87)90121-4 Degueurce, F., Abrous, M., Dreyfuss, G., Rondelaud, D. and Gevrey, J. (1999). Paramphistomum daubneyi and Fasciola hepatica: the prevalence of natural or experimental infections in four species of freshwater snails in eastern France. Fournal of Helminthology 73, 197-202.

Dinnik, J. A. (1962). Paramphistomum daubneyi sp.nov. from cattle and its snail host in the Kenya Highlands. Parasitology 52, 143-151.

Dreyfuss, G. (2015). The mud snail (Galba truncatula) Ecology, Parasitism and Control. LAMBERT Academic Publishing, Saarbrücken, Germany. Dreyfuss, G., Abrous, M., Vignoles, P. and Rondelaud, D. (2004). Fasciola hepatica and Paramphistomum daubneyi: vertical distribution of metacercariae on plants under natural conditions. Parasitology Research 94, 70-73.

Duffie, J. A. and Beckman, W. A. (2013). Solar Engineering of Thermal Processes, 4th Edn. John Wiley \& Sons Inc., Hoboken, NJ, USA.

Fielding, A. H. and Bell, J. F. (1997). A review of methods for the assessment of prediction errors in conservation presence/absence models. Environmental Conservation 24, 38-49. http://dx.doi.org/10.1017/S0376892997000088

Fox, N. J., White, P. C. L., McClean, C. J., Marion, G., Evans, A. and Hutchings, M. R. (2011). Predicting impacts of climate change on Fasciola hepatica risk. PLoS ONE 6, e16126.

Fuertes, M., Pérez, V., Benavides, J., González-Lanza, M. C., Mezo, M., González-Warleta, M., Giráldez, F. J., Fernández, M., Manga-González, M. Y. and Ferreras, M. C. (2015). Pathological changes in cattle naturally infected by Calicophoron daubneyi adult flukes. Veterinary Parasitology 209, 188-196. http://dx.doi.org/10.1016/j.vetpar. 2015.02.034

Gonzalez-Warleta, M., Lladosa, S., Castro-Hermida, J. A., Martinez-Ibeas, A. M., Conesa, D., Munoz, F., Lopez-Quilez, A., Manga-Gonzalez, Y. and Mezo, M. (2013). Bovine paramphistomosis in Galicia (Spain): prevalence, intensity, aetiology and geospatial distribution of the infection. Veterinary Parasitology 191, 252-263.

Gordon, H. M. and Boray, J. C. (1970). Controlling liver-fluke: a case for wildlife conservation? Veterinary Record 86, 288-289.

Gordon, D., Zadoks, R., Skuce, P. and Sargison, N. (2012). Confirmation of triclabendazole resistance in liver fluke in the UK. Veterinary Record 171, 159-160.

Gordon, D. K., Roberts, L. C.P., Lean, N., Zadoks, R. N., Sargison, N. D. and Skuce, P. J. (2013). Identification of the rumen fluke, Calicophoron daubneyi, in GB livestock: possible implications for liver fluke diagnosis. Veterinary Parasitology 195, 65-71.

Goumghar, M. D., Abrous, M., Ferdonnet, D., Dreyfuss, G. and Rondelaud, D. (2000). Prevalence of Haplometra cylindracea infection in 
three species of Lymnaea snails in central France. Parasitology Research 86, 337-339.

Henrys, P.A., Keith, A.M., Robinson, D. A. and Emmett, B. A. (2012). Model Estimates of Topsoil pH and Bulk Density [Countryside Survey]. NERC Environmental Information Data Centre. http://dx.doi.org/ 10.5285/5dd624a9-55c9-4cc0-b366-d335991073c7

Henrys, P. A., Keith, A. M., Robinson, D. A. and Emmett, B. A. (2014). Model Estimates of Topsoil Moisture [Countryside Survey]. NERC Environmental Information Data Centre. http://dx.doi.org/10.5285/ 8db84900-5fdb-43be-a607-e56c843d9b87

Horak, I. G. (1967). Host-parasite relationships of Paramphistomum microbothrium Fischoeder, 1901, in experimentally infested ruminants, with particular reference to sheep. Onderstepoort Fournal of Veterinary Research 34, 451-540.

Howell, A., Baylis, M., Smith, R., Pinchbeck, G. and Williams, D. (2015). Epidemiology and impact of Fasciola hepatica exposure in highyielding dairy herds. Preventive Veterinary Medicine 121, 41-48. http:// dx.doi.org/10.1016/j.prevetmed.2015.05.013

Huson, K., Brophy, P., Morphew, R. and Mackintosh, N. (2015). Identification of the rumen fluke Calicophoron daubneyi infecting cattle in Wales. Advances in Animal Biosciences 6, 183. http://dx.doi.org/10.1017/ S2040470015000035

Jones, R., Williams, H., Dalesman, S. and Brophy, P. (2015). Confirmation of Galba truncatula as an intermediate host snail for Calicophoron daubneyi in Great Britain, with evidence of alternative snail species hosting Fasciola hepatica. Parasites \& Vectors 8, 656.

Kajugu, P.E., Hanna, R. E. B., Edgar, H. W., McMahon, C., Cooper, M., Gordon, A., Barley, J. P., Malone, F. E., Brennan, G. P. and Fairweather, I. (2015). Fasciola hepatica: specificity of a coproantigen ELISA test for diagnosis of fasciolosis in faecal samples from cattle and sheep concurrently infected with gastrointestinal nematodes, coccidians and/or rumen flukes (paramphistomes), under field conditions. Veterinary Parasitology 212, 181-187. http://dx.doi.org/10.1016/j.vetpar. 2015.07.018

Kearse, M., Moir, R., Wilson, A., Stones-Havas, S., Cheung, M., Sturrock, S., Buxton, S., Cooper, A., Markowitz, S., Duran, C., Thierer, T., Ashton, B., Mentjies, P. and Drummond, A. (2012). Geneious basic: an integrated and extendable desktop software platform for the organization and analysis of sequence data. Bioinformatics 28, $1647-1649$.

Lobo, J. M., Jiménez-Valverde, A. and Real, R. (2008). AUC: a misleading measure of the performance of predictive distribution models. Global Ecology and Biogeography 17, 145-151.

Mage, C., Bourgne, H., Toullieu, J. M., Rondelaud, D. and Dreyfuss, G. (2002). Fasciola hepatica and Paramphistomum daubneyi: changes in prevalences of natural infections in cattle and in Lymnaea truncatula from central France over the past 12 years. Veterinary Research 33, 439-447.

Malrait, K., Verschave, S., Skuce, P., Van Loo, H., Vercruysse, J. and Charlier, J. (2015). Novel insights into the pathogenic importance, diagnosis and treatment of the rumen fluke (Calicophoron daubneyi) in cattle. Veterinary Parasitology. http://dx.doi.org/10.1016/j.vetpar.2014.10.033. Martinez-Ibeas, A. M., Gonzalez-Warleta, M., MartinezValladares, M., Castro-Hermida, J. A., Gonzalez-Lanza, C., Minambres, B., Ferreras, C., Mezo, M. and Manga-Gonzalez, M. Y. (2013). Development and validation of a mtDNA multiplex PCR for identification and discrimination of Calicophoron daubneyi and Fasciola hepatica in the Galba truncatula snail. Veterinary Parasitology 195, 57-64. Mason, C., Stevenson, H., Cox, A. and Dick, I. (2012). Disease associated with immature paramphistome infection in sheep. Veterinary Record 170, 343-344

McCann, C. M., Baylis, M. and Williams, D. J. L. (2010). The development of linear regression models using environmental variables to explain the spatial distribution of Fasciola hepatica infection in dairy herds in England and Wales. International Fournal of Parasitology 40, 1021-1028. McNemar, Q. (1947). Note on the sampling error of the difference between correlated proportions or percentages. Psychometrika 12,153-157. Met-Office (2016). Temperature, rainfall and sunshine time-series [Online]. http://www.metoffice.gov.uk/climate/uk/summaries/actualmonthly. Millar, M., Colloff, A. and Scholes, S. (2012). Disease associated with immature paramphistome infection. Veterinary Record 171, 509-510. Mitchell, A., Bourn, D., Mawdsley, J., Wint, W., Clifton-Hadley, R. and Gilbert, M. (2005). Characteristics of cattle movements in Britain an analysis of records from the Cattle Tracing System. Animal Science 80, 265-273
NADIS (2016). NADIS parasite forecast [Online]. http://www.nadis.org. uk/parasite-forecast.aspx

O'Toole, A., Browne, J.A., Hogan, S., Bassiere, T., DeWaal, T., Mulcahy, G. and Zintl, A. (2014). Identity of rumen fluke in deer. Parasitology Research 113, 4097-4103.

Ollerenshaw, C. B. and Rowlands, W. T. (1959). A method of forecasting the incidence of fascioliasis in Anglesey. Veterinary Record 71, 591-598. Ordnance Survey (2016). Mapping data and geographic information from OS [Online]. https://www.ordnancesurvey.co.uk/opendatadownload/products.html.

Perry, M. and Hollis, D. (2005). The generation of monthly gridded datasets for a range of climatic variables over the UK. International Fournal of Climatology 25, 1041-1054

Pillers, A. W. N. (1922). Paramphistomum cervi from a cow in Cheshire. Veterinary fournal 78, 292-293.

Pritchard, G. C., Forbes, A. B., Williams, D. J. L., SalimiBejestani, M. R. and Daniel, R. G. (2005). Emergence of fasciolosis in cattle in East Anglia. Veterinary Record 157, 578-582.

Rangel, T. F., Diniz-Filho, J. A. F. and Bini, L. M. (2010). SAM: a comprehensive application for spatial analysis in Macroecology. Ecography 33, 46-50.

Rawlins, B. G., McGrath, S. P., Scheib, A. J., Breward, N., Cave, M. Lister, T. R., Ingham, M., Gowing, C. and Carter, S. (2012). The Advanced Soil Geochemical Atlas of England and Wales. British Geological Survey, Keyworth. http://www.bgs.ac.uk/gbase/advsoilatlasEW.html.

Reilly, L. A. and Courtenay, O. (2007). Husbandry practices, badger sett density and habitat composition as risk factors for transient and persistent bovine tuberculosis on UK cattle farms. Preventive Veterinary Medicine $\mathbf{8 0}$, 129-142. http://dx.doi.org/10.1016/j.prevetmed.2007.02.002.

Rieu, E., Recca, A., Bénet, J. J., Saana, M., Dorchies, P. and Guillot, J. (2007). Reliability of coprological diagnosis of Paramphistomum sp. infection in cows. Veterinary Parasitology 146, 249-253. http://dx.doi.org/10. 1016/j.vetpar.2007.02.033

Rondelaud, D., Hourdin, P., Vignoles, P. and Dreyfuss, G. (2005). The contamination of wild watercress with Fasciola hepatica in central France depends on the ability of several lymnaeid snails to migrate upstream towards the beds. Parasitology Research 95, 305-309.

Rondelaud, D., Vignoles, P. and Dreyfuss, G. (2007). Parasite development and visceral pathology in Galba truncatula co-infected with Fasciola hepatica and Paramphistomum daubneyi. Fournal of Helminthology 81, 317-322.

Sargison, N., Francis, E., Davison, C., Bronsvoort, B. M. d., Handel, I. and Mazeri, S. (2016). Observations on the biology, epidemiology and economic relevance of rumen flukes (Paramphistomidae) in cattle kept in a temperate environment. Veterinary Parasitology 219, 7-16. http:// dx.doi.org/10.1016/j.vetpar.2016.01.010.

Schmitz, C. (2015). LimeSurvey: An Open Source Survey Tool. LimeSurvey Project Hamburg, Germany. http://www.limesurvey.org.

Schweizer, G., Braun, U., Deplazes, P. and Torgerson, P. R. (2005)

Estimating the financial losses due to bovine fasciolosis in Switzerland. Veterinary Record 157, 188-193.

Sey, O. (1980). Revision of the amphistomes of European ruminants. Parasitologia Hungarica 13, 13-25.

Toolan, D. P., Mitchell, G., Searle, K., Sheehan, M., Skuce, P. J. and Zadoks, R. N. (2015). Bovine and ovine rumen fluke in IrelandPrevalence, risk factors and species identity based on passive veterinary surveillance and abattoir findings. Veterinary Parasitology 212, 168-174.

VIDA (2016a). Veterinary investigation diagnostic analysis data (includes AHPA and SRUC data). Unpublished raw data.

VIDA (2016b). Rumen fluke species ID in English reindeer. Unpublished raw data.

Whitelaw, A. and Fawcett, A. R. (1982). Biological control of liver fluke. Veterinary Record 110, 500-501

Williams, H.W., Cross, D.E., Crump, H. L., Drost, C. J. and Thomas, C. J. (2015). Climate suitability for European ticks: assessing species distribution models against null models and projection under AR5 climate. Parasites \& Vectors 8, 1-15.

Zhang, J. and Yu, K. F. (1998). What's the relative risk?: a method of correcting the odds ratio in cohort studies of common outcomes. $\mathcal{F} A M A 280$, 1690-1691.

Zintl, A., Garcia-Campos, A., Trudgett, A., Chryssafidis, A. L., Talavera-Arce, S., Fu, Y., Egan, S., Lawlor, A., Negredo, C., Brennan, G., Hanna, R. E., De Waal, T. and Mulcahy, G. (2014). Bovine paramphistomes in Ireland. Veterinary Parasitology 204, 199-208. http://dx.doi.org/10.1016/j.vetpar.2014.05.024 